\title{
A carbonate-fluoride defect model for carbonate-rich fluorapatite
}

Haohao $\mathrm{Yi}^{1}$, Etienne Balan ${ }^{1}$, Christel Gervais ${ }^{2}$, Loïc Segalen ${ }^{3}$, Frank Fayon ${ }^{4}$, Damien Roche ${ }^{3}$, Alain Person ${ }^{3}$, Guillaume Morin ${ }^{1}$, Maxime Guillaumet ${ }^{1}$, Marc Blanchard ${ }^{1}$, Michele Lazzeri ${ }^{1}$, Florence Babonneau ${ }^{2}$.

${ }^{1}$ Institut de Minéralogie et Physique des Milieux Condensés (IMPMC), UMR CNRS 7590, UMR IRD 206, UPMC Univ. Paris 06, 4 place Jussieu, 75252 Paris, cedex 05 France

${ }^{2}$ Laboratoire de Chimie de la Matière Condensée de Paris, UPMC Univ. Paris 06 \& CNRS, Collège de France, 11, Place Marcelin Berthelot, 75005, Paris, France

${ }^{3}$ UPMC Univ Paris 06, UMR 7193 ISTEP, Biominéralisations et Environnements Sédimentaires, 4 place Jussieu, 75252 Paris, cedex 05 France

${ }^{4}$ Conditions Extrêmes et Matériaux: Haute Température et Irradiation (CEMHTI), UPR 3079 CNRS, 1D Avenue de la Recherche Scientifique, 45071 Orléans cedex 2, France

Corresponding author: Haohao Yi

E-mail : Haohao.Yi@impmc.upmc.fr 


\section{Abstract}

We propose a microscopic model for the dominant carbonate for phosphate substitution in fluorapatite. A well-crystallized sedimentary fluorapatite sample containing $\sim 2.3 \pm 0.8$ wt $\%$ of carbonate was investigated using Fourier-transform infrared spectroscopy (FTIR) and ${ }^{13} \mathrm{C}$ and ${ }^{19} \mathrm{~F}$ magic-angle spinning nuclear magnetic resonance (MAS NMR). About $75 \%$ of carbonate groups replace the phosphate group ("B-site"), whereas a lesser contribution from carbonate groups located in the structural channels ("A-site") is observed. Beside the dominant ${ }^{19} \mathrm{~F}$ NMR signal of channel ions at $\sim-102 \mathrm{ppm}$, an additional signal corresponding to $\sim 8 \%$ of fluoride ions is observed at $-88 \mathrm{ppm} .{ }^{19} \mathrm{~F}$ double quantum-single quantum (DQSQ) MAS NMR and ${ }^{13} \mathrm{C}\left\{{ }^{19} \mathrm{~F}\right\}$ frequency-selective Rotational Echo DOuble Resonance (REDOR) experiments evidence that this additional signal corresponds to isolated fluoride ions in the apatite structure, located in close proximity of substituted carbonate groups. Density functional theory (DFT) calculations allow us to propose a composite carbonatefluoride tetrahedron defect model accounting for these experimental observations. The planar carbonate ion defines the sloping face of the tetrahedron opposite a fluoride ion defining the remaining vertex, together replacing the tetrahedral phosphate ion. This "francolite-type" defect leads to a diagnostic narrow IR absorption band at $864 \mathrm{~cm}^{-1}$ that could be used as a guide to, e.g., detect the incipient transformation of fossil bone and teeth samples.

\section{Introduction}

Apatite, $\mathrm{Ca}_{5}\left(\mathrm{PO}_{4}\right)_{3}(\mathrm{OH}, \mathrm{F}, \mathrm{Cl})$, is an accessory phase occurring in many igneous, metamorphic, and sedimentary rocks. World phosphorus resources consist mainly of sedimentary deposits of carbonate-bearing fluorapatite, referred to as "francolite" (Knudsen and Gunter 2002), while carbonate-bearing hydroxyapatite is the major inorganic component of vertebrate skeletons (Elliott 2002). The flexibility of the apatite structure enables significant chemical variations, among which carbonate group incorporation is of peculiar 
importance (Leventouri et al. 2000; Pan and Fleet 2002; Peroos et al. 2006). Structural carbonate groups have significant effects on apatite physical and chemical properties (Elliott 2002) and can be used as proxies of past environmental conditions in fossil samples (Kohn and Cerling 2002). They can substitute at the phosphate tetrahedral site (B-site) or in the structural channels located on the hexagonal symmetry axis (A-site), each site leading to specific Fourier-transform infrared (FTIR) and nuclear magnetic resonance (NMR) spectroscopic signatures (e.g., Beshah et al. 1990; Elliott 2002). Despite numerous studies, detailed atomic-scale models of carbonate groups in apatite are still debated (e.g., Regnier et al. 1994; Pan and Fleet 2002; Astala and Stott 2005). In particular, the early model for local charge compensation of carbonate by fluoride ions at B-site in "francolite" samples with excess fluoride (McClellan and Lehr 1969) has been challenged by the theoretical modeling of a tetrahedral $\mathrm{CO}_{3} \mathrm{~F}^{3-}$ species by Regnier et al. (1994). More recent electron paramagnetic resonance (Nokhrin et al. 2006) and NMR (Mason et al. 2009) investigations of carbonatebearing fluorapatite samples did not find any evidence of interaction between carbon and fluorine atoms.

In the present study, incorporation of carbonate in "francolite" is investigated by experiment and theory, using temperature-dependent FTIR spectroscopy, ${ }^{13} \mathrm{C}$ and ${ }^{19} \mathrm{~F}$ NMR spectroscopy, and first-principles quantum-mechanical calculations. Our results evidence that the local charge compensation of carbonate by fluoride ion does occur in the B-type carbonate site of "francolite". A consistent and stable atomic-scale model of this "francolite-type" defect is proposed, in which the planar carbonate group occupies a sloping face of the tetrahedral site and a fluoride ion is located at the remaining vertex.

\section{Sample description}

The investigated sample originates from the sedimentary phosphate deposit of Taiba 
(Senegal) (Morin et al. 2002). It contains $\sim 90 \mathrm{wt} \%$ of highly crystalline fluorapatite, occurring as hexagonal prismatic particles. Associated phases are quartz $(7 \mathrm{wt} \%)$ and crandallite (2 wt $\%)$, with traces of goethite $(<1 \mathrm{wt} \%)$ and dioctahedral smectite $(<1 \mathrm{wt} \%)$. Lattice parameters of the fluorapatite $(a=9.357(2) \AA, c=6.891(2) \AA)$ are consistent with those of a carbonate-bearing fluorapatite, containing $2.3 \pm 0.8 \mathrm{wt} \%$ of carbonate (Gulbrandsen 1970; McClellan 1980). The fluoride content determined by wet chemical analysis is 3.7(1) wt $\%$.

Details of the experimental spectroscopic measurements and periodic density functional theory calculations are described in the electronic supplementary information.

\section{Results and discussions}

The room-temperature powder IR absorption spectrum of the sample (Fig. 1a) displays the absorption bands characteristic of natural carbonate-bearing apatites (LeGeros et al. 1969, Elliott 2002). Phosphate groups lead to intense bands at 569, 578 and $605 \mathrm{~cm}^{-1}\left(v_{4} \mathrm{PO}_{4}\right.$ bending modes) and 1043 and $1096 \mathrm{~cm}^{-1}$ ( $v_{3} \mathrm{PO}_{4}$ stretching modes). A weaker and narrower (full width at half-maximum $(\mathrm{FWHM}) \sim 4 \mathrm{~cm}^{-1}$ at $10 \mathrm{~K}$ ) band at $966 \mathrm{~cm}^{-1}$ is related to the $v_{1}$ $\mathrm{PO}_{4}$ stretching modes. Its width mostly depends on microscopic sources of broadening and attests to the high crystalline-quality of the sample (Balan et al. 2011). Broader (FWHM $\sim 15$ $\mathrm{cm}^{-1}$ at $10 \mathrm{~K}$ ) bands related to the two anti-symmetric $v_{3} \mathrm{CO}_{3}$ stretching modes are observed at 1429 and $1454 \mathrm{~cm}^{-1}$. Their frequency is consistent with a dominant incorporation of carbonate groups at the B site (1410-1430 and 1450-1460 $\mathrm{cm}^{-1}$; LeGeros et al. 1969). The weaker absorption band of the $v_{2} \mathrm{CO}_{3}$ bending mode is observed at $\sim 864 \mathrm{~cm}^{-1}$; consistent with the "francolite" spectra previously reported by, e.g., Regnier et al. (1994) and Fleet (2009). It corresponds to the out-of-plane oscillating motion of $\mathrm{C}$ atoms. A fit of the $v_{2}$ band measured at $10 \mathrm{~K}$ (Fig. 1b) shows that $\sim 70 \%$ of the signal area corresponds to a narrow Lorentzian band. Other components at $878 \mathrm{~cm}^{-1}\left(\sim 6 \%\right.$ of the signal area) and $859 \mathrm{~cm}^{-1}(\sim 24 \%$ of the signal area) 
are ascribed to minor proportions of A-type and to unspecified environments (potentially Atype) of carbonate groups, respectively (Rey et al. 1989; Elliott 2002; Fleet 2009). The $v_{2} \mathrm{CO}_{3}$ band displays the usual quantum saturation behavior at low-temperature (Balan et al. 2011), with a characteristic saturation temperature of the linewidth of $\sim 500 \mathrm{~K}$ (Figs. 1c and d). The FWHM of the main component at $10 \mathrm{~K}$ is $\sim 3.3 \mathrm{~cm}^{-1}$. This small linewidth indicates that the corresponding carbonate defect occurs in a well-defined molecular environment of the apatite structure, precluding the occurrence of multiple charge-balance mechanisms.

The ${ }^{13} \mathrm{C}$ MAS NMR spectrum exhibits a relatively narrow signal at $170.4 \mathrm{ppm}$ (Fig. 2a) in good agreement with previous observations, and characteristic of carbonate groups on the B-site (Beshah et al. 1990). The peak is slightly asymmetric, suggesting the presence of residual carbonates on the A-site (around $169 \mathrm{ppm}$ ). A simulation with two components at 170.4 and 168.7 indicates that the dominant B-site represents $\sim 75 \%$ of the total signal (Fig. 2a), roughly consistent with FTIR observations. The ${ }^{19}$ F MAS NMR spectrum (Fig. 2b) displays a main signal at $\sim-102 \mathrm{ppm}$ (maximum at $102.2 \mathrm{ppm}$ ) with a broad and slightly asymmetric lineshape, assigned to fluoride ions in the structural channels (Mason et al. 2009). The linewidth of this intense peak does not vary with the spinning frequency and is mainly due to a distribution of ${ }^{19} \mathrm{~F}$ isotropic chemical shift which reflects a distribution of the environment of the fluoride ions in the channels. A less intense peak is also present at -88 ppm, representing $\sim 8 \%$ of the total fluorine contribution (Fig. 2b). This signal was also present in the carbonate fluorapatite ("stafellite") sample investigated by Mason et al. (2009). It is absent in measurements performed on a carbonate-poor fluorapatite sample from Durango, Mexico (not shown). Although likely related to B-site carbonate substitution, no conclusive assignment was achieved for this peak (Mason et al. 2009). Two-dimensional ${ }^{19} \mathrm{~F}$ homonuclear DQ-SQ MAS NMR experiments (Fig. 2c), which have been shown to probe F-F interatomic proximities up to $4.5 \AA$ (Wang et al. 2009), confirm that the signal at $-88 \mathrm{ppm}$ 
corresponds to a second $\mathrm{F}$ environment in the apatite structure. The absence of autocorrelation peak for this signal indicates that the F-F distances between the corresponding F sites exceed $4.5 \AA$, whereas the observed intense cross-correlation peaks show that these sites are in the close vicinity of $\mathrm{F}$ ions contributing to the peak at $-102 \mathrm{ppm}$. It thus corresponds to isolated defects in the apatite structure. In addition, a natural-abundance frequency selective ${ }^{13} \mathrm{C}\left\{{ }^{19} \mathrm{~F}\right\}$ REDOR experiment which allows the recoupling of the heteronuclear dipolar interactions between ${ }^{13} \mathrm{C}$ resonances and a single selected ${ }^{19} \mathrm{~F}$ site, was employed to probe $\mathrm{C}-\mathrm{F}$ inter-atomic proximities. It shows that the signal at $-88 \mathrm{ppm}$ exhibits relatively large ${ }^{19} \mathrm{~F}-{ }^{13} \mathrm{C}$ dipolar couplings consistent with an F-C inter-atomic distance in the range from 2.5 to $2.7 \AA$ (Fig. 2d).

Considering these experimental results, as well as previous polarized IR measurements (Elliott 1964) and XRD pattern refinements (Fleet and Liu 2004), a model of "francolitetype" carbonate for phosphate substitution is built by incorporating one carbon atom at the center of a sloping face of the tetrahedral site and by substituting a fluoride ion for the opposite oxygen (Fig. 3). The occurrence of such a defect in a single cell of fluorapatite $\left(\mathrm{Ca}_{10}\left(\mathrm{PO}_{4}\right)_{5}\left(\mathrm{CO}_{3} \mathrm{~F}\right) \mathrm{F}_{2}\right)$ corresponds to a concentration of $6.0 \mathrm{wt} \%$ of $\mathrm{CO}_{3}$. The unit-cell parameters of the model are fixed at the relaxed values previously obtained for fluorapatite ( $a$ $=9.48 \AA, c=6.9 \AA$; Balan et al. 2011). Energy minimization and relaxation of atomic positions evidence that the proposed configuration corresponds to the stable state of the defect. The C-O bond lengths range between 1.29 and $1.31 \AA$ (Table 1). The theoretical distance between the $\mathrm{C}$ and $\mathrm{F}$ atom is $2.47 \AA$, in good agreement with the result of the ${ }^{13} \mathrm{C}\left\{{ }^{19} \mathrm{~F}\right\}$ REDOR experiment. At variance with the theoretical model of the tetrahedral carbonate defect investigated by Regnier et al. (1994), the planar geometry of the carbonate group is preserved and the fluoride ion does not migrate to an interstitial position. 
The comparison of the theoretical IR absorption spectrum with the experimental one confirms the assignment of the main absorption bands to carbonate or phosphate group's vibrational modes (Fig. 1a, Table 1). Discrepancies observed between theoretical and experimental frequencies are similar to those observed in previous theoretical investigations of minerals using the PBE functional (e.g., Balan et al. 2011). Compared to pure fluorapatite, additional vibrational modes of phosphate groups are active because of the lower symmetry of the defective crystal. The $v_{1} \mathrm{PO}_{4}$ modes are spread over $\sim 6 \mathrm{~cm}^{-1}$ (Table 1), which may contribute to the broadening of the $v_{1} \mathrm{PO}_{4}$ band in carbonate-bearing apatite samples (Antonakos et al. 2007). As usually observed for polar materials, intense absorption bands are also shifted with respect to the corresponding transverse-optical (TO) vibrational frequencies. These electrostatic effects significantly contribute to the inhomogeneous broadening of $v_{3}$ and $v_{4} \mathrm{PO}_{4}$ bands (Balan et al. 2011) and, to a lesser extent, of the $v_{3} \mathrm{CO}_{3}$ stretching bands (Table 1). In contrast, the $v_{2} \mathrm{CO}_{3}$ modes are almost unaffected by long-range electrostatic interactions and a narrower absorption band is consistently observed.

The ${ }^{13} \mathrm{C}$ NMR chemical shift calculated for the theoretical model of the "francolitetype" defect is at $169.8 \mathrm{ppm}$, within $1 \mathrm{ppm}$ of the experimental value $(170.4 \mathrm{ppm})$ of the Bsite in "francolite" (Fig. 2, Table 1). The three different types of fluoride ions display three different theoretical ${ }^{19} \mathrm{~F}$ NMR chemical shifts (Fig. 2, Table 1). The two channel fluoride ions (F1 and F2) are computed at -102.1 and $-103.2 \mathrm{ppm}(-102.5 \mathrm{ppm}$ for a pure fluorapatite). These values support the assignment of the peak experimentally observed at $\sim-102 \mathrm{ppm}$ to channel fluoride ions and underline the sensitivity of the ${ }^{19} \mathrm{~F}$ chemical shift to the mediumrange environment of fluorine. The experimental width of the main peak is consistent with the presence of structurally distinct channel components in the "francolite" sample. The fluoride ion (F3) forming the charge-compensated composite tetrahedron with the carbonate group defect in the "francolite-type" model is calculated at $-84 \mathrm{ppm}$, consistent with the additional 
signal observed at $-88 \mathrm{ppm}$ in the experimental spectrum. In addition, the calculated ${ }^{19} \mathrm{~F}$ chemical shift anisotropy parameters of the $\mathrm{F} 1\left(\delta_{\mathrm{CSA}}=55 \mathrm{ppm}, \eta=0.2\right), \mathrm{F} 2\left(\delta_{\mathrm{CSA}}=57.2 \mathrm{ppm}, \eta\right.$ $=0.3)$ and $\mathrm{F} 3\left(\delta_{\mathrm{CSA}}=-55.8 \mathrm{ppm}, \eta=0.5\right)$, sites are in good agreement with the values determined from the spinning sidebands intensities of the experimental ${ }^{19} \mathrm{~F}$ resonances at -102 $\operatorname{ppm}\left(\delta_{\mathrm{CSA}}=58(3) \mathrm{ppm}, \eta=0.35(5)\right)$ and $-88 \mathrm{ppm}\left(\delta_{\mathrm{CSA}}=-57(3) \mathrm{ppm}, \eta=0.5(1)\right)$.

Summarizing these results, spectroscopic FTIR and ${ }^{13} \mathrm{C}$ NMR measurements consistently indicate that, in the investigated "francolite" sample, carbonate ions are mostly incorporated in the B-site of the structure. The dominant carbonate molecular environment, as probed by the IR linewidth, is weakly distributed, indicating the occurrence of a single dominant charge balance mechanism. The concomitant detection of an additional fluoride environment in the ${ }^{19} \mathrm{~F}$ NMR spectrum suggests that non-channel fluoride ions located in the apatite structure are candidates for the electrostatic charge compensation of carbonate groups incorporated at the B-site of the structure. The close proximity of these fluoride ions to carbonate groups is further attested by ${ }^{13} \mathrm{C}\left\{{ }^{19} \mathrm{~F}\right\}$ REDOR experiments. In parallel, the theoretical structural and spectroscopic properties of a carbonate-bearing fluorapatite model are robustly tested against experimental observations. This body of evidence leads us to propose that a planar carbonate ion located on the sloping face of the phosphate tetrahedron facing a fluoride ion located at the remaining tetrahedron apex is a realistic model of the carbonate site in "francolite". It should be noticed that this defect does not correspond to a tetrahedral species with $\mathrm{sp}^{3}$ hybridization of carbon orbitals, which is consistent with the conclusions of Regnier et al. (1994). To our knowledge, this is the first direct evidence that carbonate groups at the tetrahedral phosphate site are locally charge-compensated by fluoride ions. In samples with nearly stoichiometric $\mathrm{F}$ content, this implies that an equivalent proportion of channel sites is balanced by other species, most likely A-site carbonate groups in the present case. We further suggest that the narrow absorption band observed at $864 \mathrm{~cm}^{-1}$ 
could be used as diagnostic evidence for the occurrence of this atomic-scale environment in natural apatite and may serve as a guide to, e.g., unravel the incipient recrystallization of fossil bone and teeth samples.

\section{Acknowledgments}

We thank Ian Swainson, and three anonymous reviewers for their fruitful comments. We thank William Sacks for his proofreading. This work was performed using HPC resources from GENCI-IDRIS (Grants 2012-041519 and 091461). Funding by the UPMC Emergence program, the CNRS-INSU "INTERRVIE" program, the ANR "BLANC" program (ANR-09BLAN-0120-01) and the TGIR RMN THC FR3050 are acknowledged.

\section{References}

Astala, R. and Stott, M.J. (2005) First principles investigation of mineral component of bone: $\mathrm{CO}_{3}$ substitutions in hydroxyapatite. Chemistry of Materials, 17, 4125-4133.

Antonakos, A., Liarokapis, E., and Leventouri, T. (2007) Micro-Raman and FTIR studies of synthetic and natural apatites. Biomaterials, 28, 3043-3054.

Balan, E., Delattre, S., Roche, D., Segalen, L., Morin, G., Guillaumet, M., Blanchard, M., Lazzeri, M., Brouder, C., and Salje, E.K.H. (2011) Line-broadening effects in the powder infrared spectrum of apatite. Physics and Chemistry of Minerals, 38, 111-122.

Beshah, K., Rey, C., Glimcher, M.J., Schimizu, M., and Griffin, R.G. (1990) Solide state ${ }^{13}$ C and proton NMR-studies of carbonate-containing calcium phosphates and enamel. Journal of Solid State Chemistry, 84, 71-81.

Elliott, J.C. (1964) The crystallographic structure of dental enamel and related apatites. PhD thesis, University of London. 
Elliott, J.C. (2002) Calcium Phosphate Biominerals. In M.L. Kohn, J.R., and J.M. Hughes, Eds., Phosphates - Geochemical, Geobiological, and Materials Importance, 48, p. 427453. Reviews in Mineralogy and Geochemistry, Mineralogical Society of America, Chantilly, Virginia.

Fleet, M.E. (2009) Infrared spectra of carbonate apatites: $v_{2}$-Region bands. Biomaterials, 30, $1473-1481$.

Fleet, M.E. and Liu, X. (2004) Location of type B carbonate ion in type A-B carbonate apatite synthesized at high pressure. Journal of Solid State Chemistry, 177, 3174-3182.

Gulbrandsen R.A. (1970) Relation of carbon dioxide content of apatite of the Phosphoria formation to the regional facies. U.S. Geological Survey Professional Paper, 700-B, B9B13.

Knudsen, A.C. and Gunter, M.E. (2002) Sedimentary phosphates - An example: Phosphoria formation, Southern Idaho, U.S.A. In M.L. Kohn, J.R., and J.M. Hughes, Eds., Phosphates - Geochemical, Geobiological, and Materials Importance, 48, p. 363-390. Reviews in Mineralogy and Geochemistry, Mineralogical Society of America, Chantilly, Virginia.

Kohn, M.J. and Cerling, T.E. (2002) Stable isotope compositions of biological Apatite. In M.L. Kohn, J.R., and J.M. Hughes, Eds., Phosphates - Geochemical, Geobiological, and Materials Importance, 48, p. 455-488. Reviews in Mineralogy and Geochemistry, Mineralogical Society of America, Chantilly, Virginia.

LeGeros, R.Z., Trautz, O.R., Klein, E., and LeGeros, J.P. (1969) Two types of carbonate substitution in the apatite structure. Experientia, 25, 5-7.

Leventouri, T., Chakoumakos, B.C., Moghaddam, H.Y., and Perdikatsis, V. (2000) Powder neutron diffraction studies of a carbonate fluorapatite. Journal of Materials Research, $15,511-517$. 
Mason, H.E., McCubbin, F.M., Smirnov, A., and Phillips, B.L. (2009) Solid-state NMR and IR spectroscopic investigation of the role of structural water and $\mathrm{F}$ in carbonate-rich fluorapatite. American Mineralogist, 94, 507-516.

McClellan, G.H. and Lehr, J.R. (1969) Crystal chemical investigation of natural apatite. American Mineralogist, 54, 1374-1391.

McClellan, G.H. (1980) Mineralogy of carbonate fluorapatites. Journal of the Geological Society, 137, 675-681.

Morin, G., Allard, T., Balan, E., Ildefonse, P., and Calas, G. (2002) Native $\mathrm{Cd}^{+}$in sedimentary fluorapatite. European Journal of Mineralogy, 14, 1087-1094.

Nokhrin, S.M. (2006) Electron paramagnetic resonance spectroscopic study of carbonatebearing fluorapatite: New defect centers and constraints on the incorporation of carbonate ions in apatites. American Mineralogist, 91, 1425-1431.

Pan, Y. and Fleet, M. (2002) Compositions of the apatite-group minerals: substitution mechanisms and controlling factors. In M.L. Kohn, J.R., and J.M. Hughes, Eds., Phosphates - Geochemical, Geobiological, and Materials Importance, 48, p. 13-50. Reviews in Mineralogy and Geochemistry, Mineralogical Society of America, Chantilly, Virginia.

Peroos, S., Du, Z., and de Leeuw, N.H. (2006) A computer modelling study of the uptake, structure and distribution of carbonate defects in hydroxy-apatite. Biomaterials, 27, $2150-2161$

Regnier, P., Lasaga, A.C., Berner, R.A., Han, O.H., and Zilm, K.W. (1994) Mechanism of $\mathrm{CO}_{3}{ }^{2-}$ substitution in carbonate-fluorapatite: Evidence from FTIR spectroscopy, ${ }^{13} \mathrm{C}$ NMR, and quantum mechanical calculation. American Mineralogist, 79, 809-818. 
Rey, C., Lian, J., Grynpas, M., Shapiro, F., Zylberberg, L., and Glimcher, M.J. (1989) Nonapatitic environments in bone mineral: FT-IR detection, biological properties and changes in several disease states. Connective Tissue Research, 21, 267-273.

Wang, Q., Hu, B., Fayon, F., Trébosc, J., Legein, C., Lafon, O., Deng, F., Amoureux, J.P. (2009) Double-quantum ${ }^{19} \mathrm{~F}-{ }^{19} \mathrm{~F}$ dipolar recoupling under ultra-fast magic angle spinning: application to the assignment of ${ }^{19} \mathrm{~F}$ NMR spectra of inorganic fluorides. Physical Chemistry Chemical Physic, 11, 10391-10395. 


\section{Figure captions}

Figure 1: (a) Experimental room temperature FTIR spectrum of the Taïba apatite sample (top) and theoretical IR absorption spectrum (bottom) of the "francolite-type" model. (b) Fit the $v_{2}$ $\mathrm{CO}_{3}$ absorption bands at $10 \mathrm{~K}$ after baseline subtraction. (c) Temperature dependence of the $v_{2} \mathrm{CO}_{3}$ absorption spectrum from $270 \mathrm{~K}$ (top) to $10 \mathrm{~K}$ (bottom) in steps of $20 \mathrm{~K}$. (d) Temperature dependence of the frequency (green circles) and linewidth (black squares) of the $v_{2} \mathrm{CO}_{3}$ band. The average linewidth parameter $\left(\Delta_{\text {corr }}\right)$ was obtained by spectral autocorrelation (Balan et al. 2011).

Figure 2: NMR spectra of the Taïba apatite sample. (a) ${ }^{13} \mathrm{C}$ MAS NMR spectrum $\left(\mathrm{B}_{0}=7.0 \mathrm{~T}\right.$, $\left.v_{\text {Rot }}=5 \mathrm{kHz}\right)$. The theoretical ${ }^{13} \mathrm{C}$ chemical shift of the "francolite-type" model $(169.8 \mathrm{ppm})$ is shown by the vertical bar. The red line is the summation of the two fitted components (b) ${ }^{19} \mathrm{~F}$ MAS NMR spectrum $\left(B_{0}=20.0 \mathrm{~T}, v_{\mathrm{Rot}}=30 \mathrm{kHz}\right)$. The theoretical ${ }^{19} \mathrm{~F}$ chemical shifts of the "francolite-type" model (Table 1) are shown by the vertical bars. (c) Two-dimensional ${ }^{19} \mathrm{~F}$ DQ-SQ MAS NMR correlation spectrum $\left(\mathrm{B}_{0}=20.0 \mathrm{~T}, v_{\mathrm{Rot}}=30 \mathrm{kHz}\right)$. (d) Experimental dipolar dephasing difference curve (black squares) obtained from ${ }^{13} \mathrm{C}\left\{{ }^{19} \mathrm{~F}\right\}$ natural-abundance frequency selective REDOR experiments $\left(B_{0}=9.4 \mathrm{~T}, v_{\mathrm{Rot}}=14 \mathrm{kHz}\right)$. A $1.0 \mathrm{~ms}$ SNOB pulse was applied on the ${ }^{19} \mathrm{~F}$ resonance at $-88 \mathrm{ppm}$. Fitted curves for a ${ }^{13} \mathrm{C}-{ }^{19} \mathrm{~F}$ isolated spin-pair with a C-F distances of $2.5 \AA$ (blue line) and $2.7 \AA$ (green line).

Figure 3: Theoretical model of carbonate B-site in fluorapatite ("francolite-type" model, $\left.\mathrm{Ca}_{10}\left(\mathrm{PO}_{4}\right)_{5}\left(\mathrm{CO}_{3} \mathrm{~F}\right) \mathrm{F}_{2}\right)$. Fluoride $\mathrm{F} 1$ and $\mathrm{F} 2$ ions are located in the channel sites. Tetrahedral sites correspond to phosphate groups. Relative to the $c$ axis, the tetrahedra display two parallel and two sloping faces. Note the planar geometry of the carbonate group and the location of the additional F3 ion at the remaining apex of the substituted tetrahedral site. 
Table 1: Room temperature absorption band wavenumbers $\left( \pm 0.5 \mathrm{~cm}^{-1}\right),{ }^{13} \mathrm{C}$ and ${ }^{19} \mathrm{~F}$ NMR chemical shifts $( \pm 0.1 \mathrm{ppm})$ and theoretical geometrical parameters of carbonates in "francolite". Theoretical transverse vibrational frequencies are reported in parentheses. Labels of oxygen atoms refer to Figure 3.

\begin{tabular}{|c|c|c|c|c|c|c|c|c|}
\hline & $\begin{array}{c}v_{2} \mathrm{CO}_{3} \\
\left(\mathrm{~cm}^{-1}\right)\end{array}$ & $\begin{array}{l}v_{3} \mathrm{CO}_{3} \\
\left(\mathrm{~cm}^{-1}\right)\end{array}$ & $\begin{array}{l}v_{3} \mathrm{CO}_{3} \\
\left(\mathrm{~cm}^{-1}\right)\end{array}$ & $\begin{array}{l}v_{1} \mathrm{PO}_{4} \\
\left(\mathrm{~cm}^{-1}\right)\end{array}$ & $\begin{array}{l}{ }^{13} \mathrm{C} \\
(\mathrm{ppm})\end{array}$ & $\begin{array}{c}{ }^{19} \mathrm{~F} \\
(\mathrm{ppm})\end{array}$ & $\begin{array}{l}\text { C-O bond } \\
\text { length }(\AA \AA)\end{array}$ & $\mathrm{O}-\mathrm{C}-\mathrm{O}$ angle $\left({ }^{\circ}\right)$ \\
\hline Experiment & 864 & 1429 & 1454 & 966 & 170.4 & $-102.2,-88.0$ & - & - \\
\hline Model ${ }^{*}$ & $\begin{array}{c}814 \\
(813)\end{array}$ & $\begin{array}{c}1380 \\
(1375)\end{array}$ & $\begin{array}{c}1421 \\
(1415)\end{array}$ & $\begin{array}{c}913 \\
(908,909 \\
910,913 \\
914)\end{array}$ & 169.8 & $-103.2(\mathrm{~F} 2)$ & $1.30(\mathrm{C}-\mathrm{O} 2)$ & $121.0(\mathrm{O} 2-\mathrm{C}-\mathrm{O} 3)$ \\
\hline
\end{tabular}


Figure 1

(a)

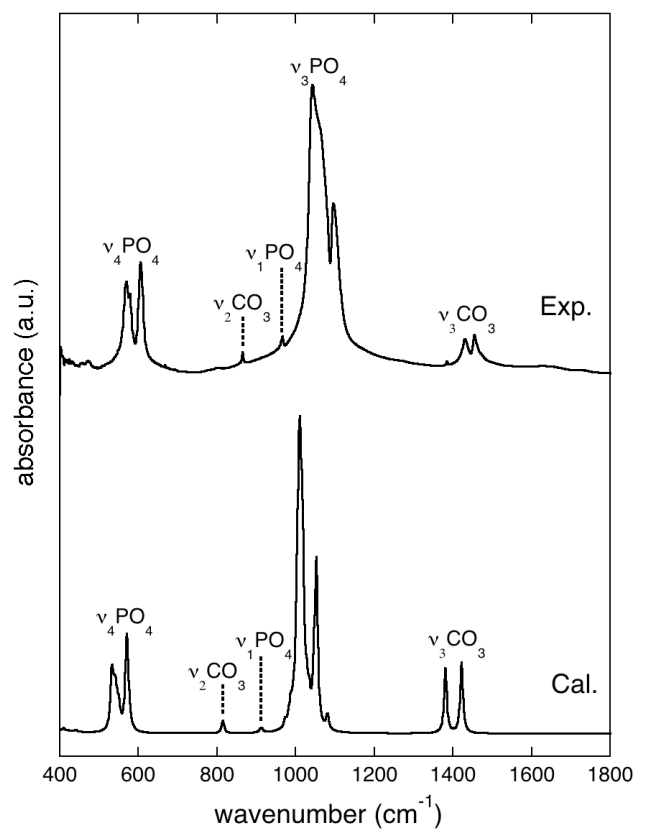

(c)

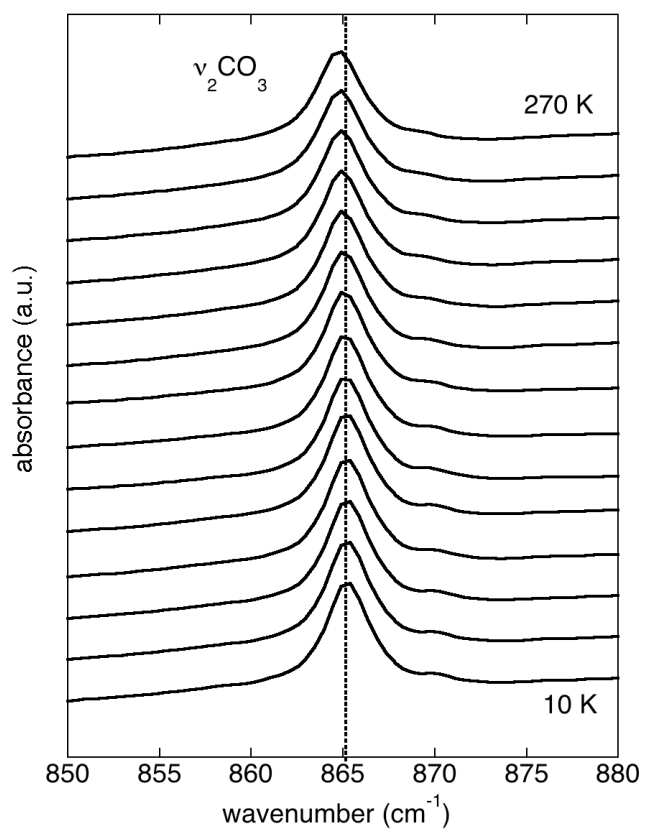

(b)

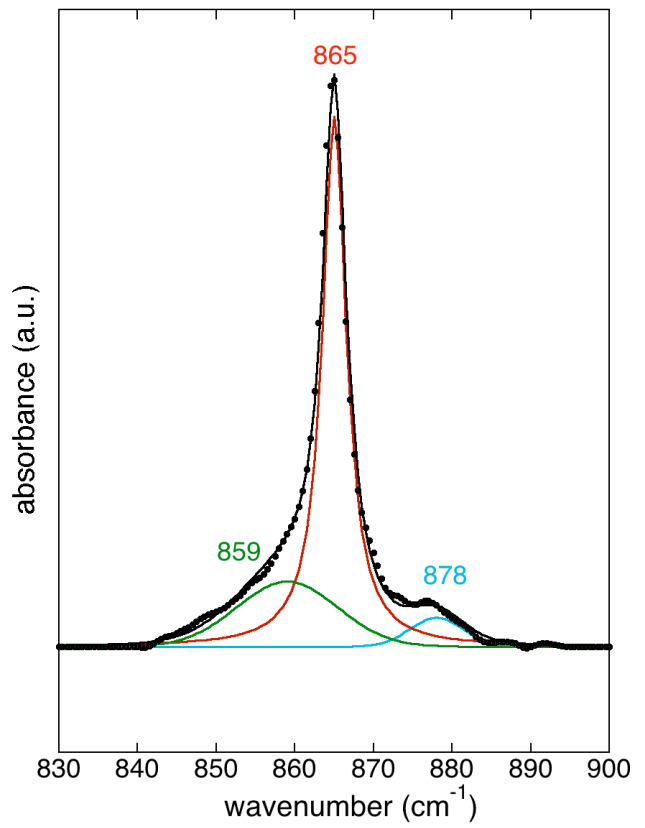

(d)

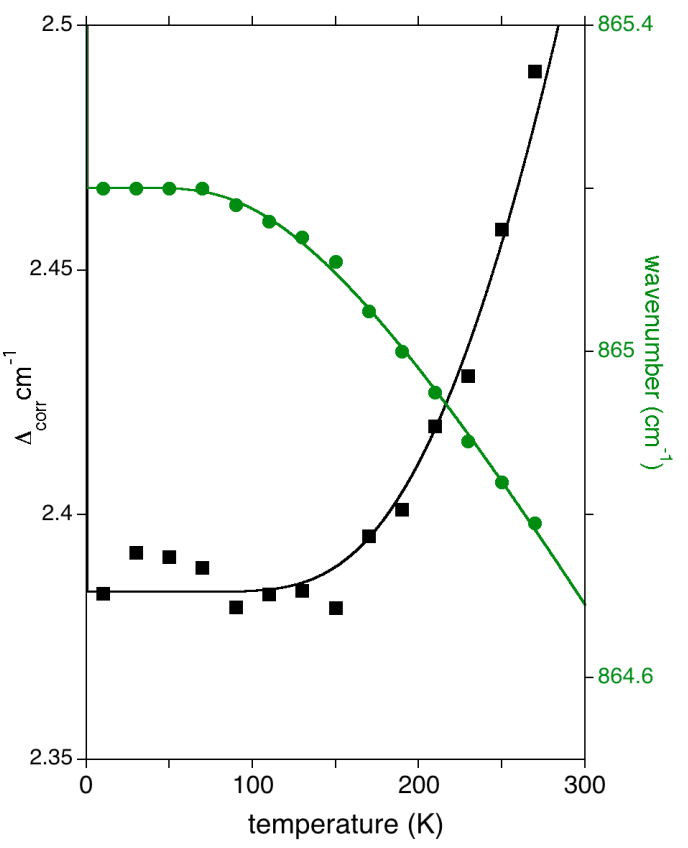


Figure 2
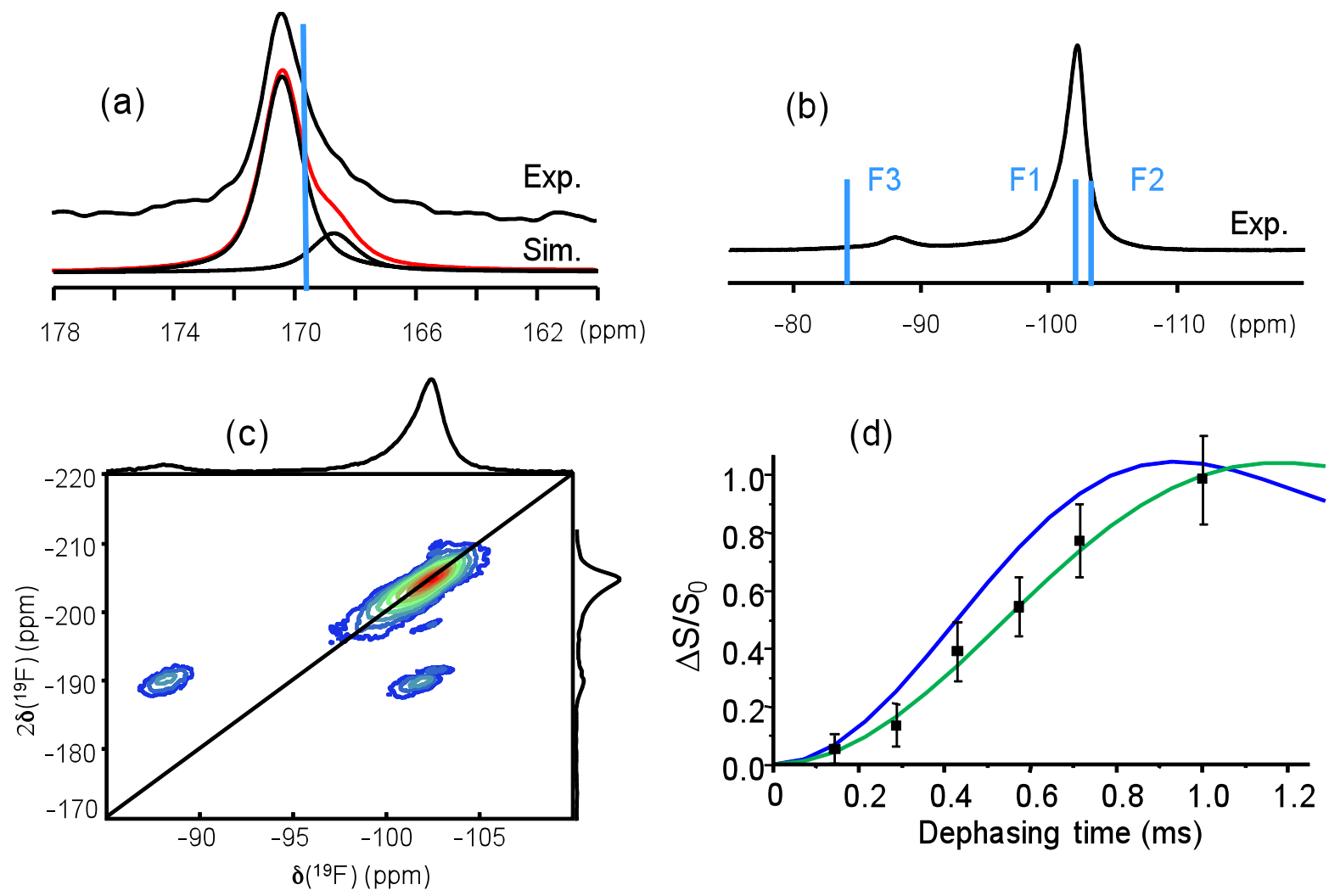
Figure 3

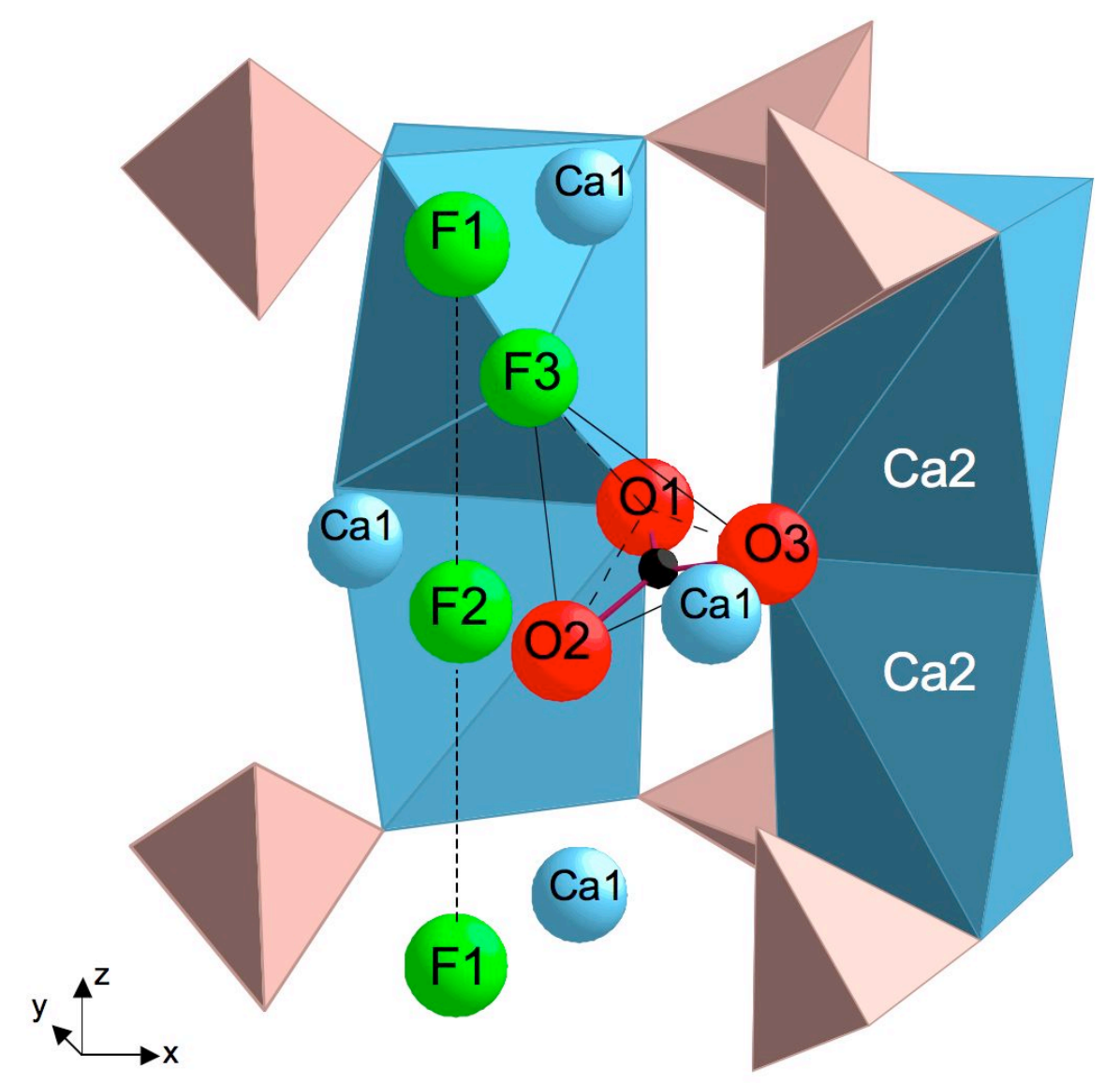

